\title{
Overexpression of Peptidases in Lactococcus and Evaluation of Their Release from Leaky Cells
}

\author{
T. R. Tuler, M. J. Callanan, and T. R. Klaenhammer \\ Department of Food Science, Southeast Dairy Foods Research Center \\ North Carolina State University, Raleigh, North Carolina, NC 27695
}

\begin{abstract}
Walker and Klaenhammer (2001) developed a novel expression system in Lactococcus lactis that facilitated the release of $\beta$-galactosidase ( $117 \mathrm{kDa}$ monomer) without the need for secretion or export signals. The system is based on the controlled expression of integrated prophage holin and lysin cassettes via a lactococcal bacteriophage $\phi 31$ transcriptional activator (Tac31A) that resides on a high-copy plasmid. Approximately $85 \%$ of $\beta$-galactosidase activity was detected in the supernatant of leaky lactococci without evidence of hindered growth, cell lysis, or membrane damage. The objective of this study was to determine if intracellular peptidases were externalized from leaky lactococci. Five $L$. lactis peptidases (PepA, PepC, PepN, PepO and PepXP) and two Lactobacillus helveticus peptidases (PepN and $\mathrm{PepO}$ ) were cloned and overexpressed on two high-copy vectors. The lactococcal peptidases were also cloned into the high-copy vector that contained the Tac31A transcriptional activator to determine if they were externalized from the leaky prophage-containing $L$. lactis subsp. lactis strain NCK203. Two of the lactococcal peptidases (PepA and PepO) required an additional strong promoter (Lactobacillus paracasei P144) and optimized assay conditions to detect enzyme activity. Results showed different levels of enzymatic overexpression associated with the cellular fraction ( 2 to 250 -fold increases in activity) and negligible amounts of activity present within the supernatant fraction ( 0 to $6 \%$ of total peptidase activity). The lactococcal phage-based protein release mechanism did not facilitate the externalization of the lactococcal peptidases investigated in this study. (Key words: Leaky Lactococcus, peptidase)
\end{abstract}

Abbreviation key: $\mathbf{C m}=$ chloramphenicol, $\mathbf{E m}=$ erythromycin, LAB = lactic acid bacteria, $\mathbf{M C A}=$ methylcoumarin, $\mathbf{P e p}=$ peptidase, $\mathbf{p N A}=$ para-nitroanilide .

Received March 6, 2002.

Accepted: April 24, 2002

Corresponding author: T. R. Klaenhammer; e-mail: klaenhammer @ncsu.edu.

\section{INTRODUCTION}

Lactic acid bacteria (LAB) are responsible for flavor and texture development of milk-based fermentation products. Of particular importance in milk fermentation is the proteolysis of casein. The LAB species have several amino acid auxotrophies, and possess proteolytic systems that enable them to acquire amino acids from casein by the use of various enzymes and transport systems. Because of their importance in cheese manufacture, the enzymatic activities of various Lactobacillus and Lactococcus strains have been studied with the objective of producing a superior final product in a shorter amount of time. The lactococcal proteolytic system consists of an extracellular, cell wall-associated proteinase, several oligopeptide and amino acid transport systems, and over ten different intracellular peptidases (Christensen et al., 1999; Kunji et al., 1996). This system is essential for their rapid growth in milk where the amount of small peptides and free amino acids is low. In addition, this process contributes to the final product by producing the precursors to volatile aromas and flavors.

Starter culture bacteria inoculated at the start of cheese making increase 100 -fold by the end of the process (5-6 hrs.) and decrease during the early stages of ripening. The rate of starter culture decline is dependent on lactose content, salt concentration, autolytic behavior, redox potentials and ripening temperatures (Farkye, 1999). The onset of cell death and subsequent lysis is very important to the cheese making process, because as intracellular enzymes are released, native milk peptides are converted into amino acids and flavor compounds. Several studies have shown that the reduction of bitterness and overall acceptable flavor development in cheese correlates to the release of these intracellular enzymes and their subsequent hydrolysis of peptides (Baankreis, 1992; Meijer et al., 1998; Prost and Chamba, 1994; Tan et al., 1993). Autolysis and intracellular enzyme release may be rate-limiting steps in the ripening process. A slow onset of lysis can cause cheese manufacturers valuable time and money. The ripening of different varieties of cheese can take as little as 4 wk to as long as $4 \mathrm{yr}$. El Soda (1997) calculated that 
ripening time for Cheddar cheese adds an additional 1.5 to 3 cents per month per pound to the cost of the final product. This makes ripening the most expensive step in the cheese making process. If ripening could be accelerated and controlled, it could improve both the efficiency and quality of the process.

Several approaches have been proposed to accelerate cheese ripening by controlling the lysis onset time using various phage- and autolysin-based mechanisms. Buist et al. (1997) induced acmA expression in Lactococcus lactis subsp. cremoris LL302 by using mitomycin and the phage $\mathrm{r} 1 \mathrm{t}$ promoter region. They reported an increase in $a c m A$ expression $4 \mathrm{~h}$ after induction, which correlated with lysis and release of intracellular proteins. This study also reported that once AcmA was released from the cell, it acted extracellularly on nonAcmA producing strains. This extracellular behavior is similar to the widespread lysis produced by released bacteriophage lysins. De Ruyter et al. (1997) combined the holin and lysin genes (lyt $A$ and $l y t H$ ) of the lactococcal bacteriophage $\phi \mathrm{US} 3$ with the nisin-inducible expression system to control the lysis of L. lactis starter cultures by using subinhibitory amounts of the lantibiotic nisin. This system provided mechanisms for both complete and partial lysis. When holin and lysin are expressed together, the complete lysis of all existing cultures occurred as a result of lysin being released into the supernatant. Other published methods of decreasing the lysis onset time also utilized phage-lysis machinery. Fiertag and McKay (1987) used chemical mutagenesis techniques to isolate temperature sensitive L. lactis $\mathrm{C} 2$ strains that lysed after $1 \mathrm{~h}$ of incubation at typical cheese cooking temperatures $\left(38-40^{\circ} \mathrm{C}\right)$. This strain harbors a resident prophage, which likely became sensitive to higher temperatures as a result of chemical mutagenesis. A shift in temperature induced the mutagenized phage into its lytic cycle leading to cell lysis. Another method controlling the onset of lysis involved overexpression of the Lactobacillus delbrueckii subsp. lactis bacteriophage LL-H lysin in Escherichia coli. Vasala et al. (1995) suggested that this lysis enzyme could be expressed in E. coli, purified, and then used as a food additive for the cheese making process. The majority of accelerated ripening models are based on control of the level and onset of cell lysis and all facilitate an early onset of cell death, which can lower cheese quality. Crow et al. stated that a balance between lysed and intact cells is important in order to create a final balanced cheese flavor and texture.

A novel enzyme delivery system created by Walker and Klaenhammer (2001) has been shown to externalize $\beta$-galactosidase ( $\beta$-gal) from $L$. lactis cells without the need for export signals and without effecting cell growth. The system is based on the controlled ex- pression of a holin and lysin cassette integrated in the host chromosome. The Tac31A transcriptional activator from a lytic lactococcal bacteriophage $\phi 31$, encoded on a high copy vector (pTRK391), activates low-level expression of the holin and lysin genes. This low level of expression results in the externalization of the large (117 kDa monomer) $\beta$-gal protein independently of cell lysis, membrane damage or reduced growth rates. The objective of this study was to determine whether leaky lactococci released intracellular peptidases into the supernatant. Leaky lactococcal starter cultures that express proteolytic enzymes and efficiently release them into the cheese matrix could potentially be used to accelerate the ripening process.

\section{MATERIALS AND METHODS}

\section{Bacterial Strains and Growth Conditions}

The strains and plasmids used in this study are listed in Table 1. L. lactis cells were grown at $30^{\circ} \mathrm{C}$ in M17 medium (Difco, Detroit, Mich.) (Terzaghi and Sandine, 1975) supplemented with $0.5 \%$ (wt/vol) glucose (GM17). Erythromycin (Em) and chloramphenicol (Cm) were used as selective agents for lactococci at a concentration of $5 \mu \mathrm{g} / \mathrm{ml}$ when needed. $E$. coli XL1-Blue strains were grown in Luria-Bertani medium (Difco) with shaking or on Brain Heart Infusion medium (BHI, Difco) supplemented with $1.5 \%$ agar. Em $(200 \mu \mathrm{g} / \mathrm{ml})$ and $\mathrm{Cm}(5 \mu \mathrm{g} /$ $\mathrm{ml}$ ) were used for selection of $E$. coli as appropriate.

\section{DNA Isolation and PCR Methods}

Genomic DNA from Lactobacillus helveticus CNRZ32 and L. lactis MG1363 was isolated as described by Walker and Klaenhammer (1994). Small-scale E. coli plasmid preparations for screening transformants were performed using alkaline sodium dodecyl sulfate lysis (Sambrook et al., 1989). Small-scale E. coli plasmid preparations used for transformation of lactococci were performed using the QIAprep Spin Miniprep kit according to the manufacturer's specifications (Qiagen, Valencia, Calif.). Small-scale isolation of lactococcal plasmid DNA was carried out as described by O'Sullivan and Klaenhammer (1993) except that ethidium bromide was not added prior to the phenol/chloroform extraction step. Standard procedures were used for all DNA manipulations described in this study (Sambrook et al., 1989). Restriction enzymes and T4 DNA ligase were obtained from Roche Molecular Biochemicals (Indianapolis, Ind.) and New England Biolabs, Inc. (Beverly, Mass.), respectively. DNA was purified using the QIAquick PCR purification kit (Qiagen) prior to use in cloning reactions. All PCR reactions were performed using standard procedures (White, 1997) and the Ex- 
Table 1. Bacterial strains and plasmids.

\begin{tabular}{|c|c|c|}
\hline Strain or plasmid & Description $^{\mathrm{a}}$ & Source and/or reference \\
\hline \multicolumn{3}{|l|}{ Bacterial strains } \\
\hline $\begin{array}{l}\text { Lb. helveticus CNRZ32 } \\
\text { L. lactis subsp. cremoris }\end{array}$ & Cheese isolate & Steele $^{\mathrm{b}}$ Bhowmik et al. (1993) \\
\hline MG1363 & Plasmid-free derivative of NCDO712 & Gasson (1983) \\
\hline L. lactis subsp. lactis & & \\
\hline NCK203 & KP1 derivative & Hill et al. (1989) \\
\hline E. coli & & \\
\hline XLI-Blue & E. coli cloning host & Gibco-BRL ${ }^{c}$ \\
\hline \multicolumn{3}{|l|}{ Plasmids } \\
\hline pTRKH2 & $\mathrm{Em}^{\mathrm{r}}$; high-copy number cloning vector & O’Sullivan and Klaenhammer (1993) \\
\hline $\mathrm{pNZ123}$ & $\mathrm{Cm}^{\mathrm{r}}$; high-copy number cloning vector & de Vos (1987) \\
\hline pTRK391 & $\mathrm{Em}^{\mathrm{r}} ; \mathrm{P}_{15 \mathrm{~A} 10}:$ lacZ.st on pTRKH 2 & Walker and Klaenhammer (2001) \\
\hline pTRK619 & $\mathrm{Em}^{\mathrm{r}} ; \mathrm{P}_{15 \mathrm{~A} 102 \mathrm{x}}:$ рерXP on pTRKH 2 & Walker and Klaenhammer (2001) \\
\hline pTRK568 & Em $^{\mathrm{r}}$; Lb. acidophilus $\mathrm{P} 6$ on pTRKH2 & Djordjevic et al. (1997) \\
\hline pTRK528 & $\mathrm{Em}^{\mathrm{r}}$; LafA translational fusion vector & Allison and Klaenhammer (1996) \\
\hline pTRK701 & $\mathrm{Em}^{\mathrm{r}} ;$ Lb. helveticus pepN on pTRKH2 & This study \\
\hline pTRK702 & $\mathrm{Cm}^{\mathrm{r}} ;$ Lb. helveticus pepN on $\mathrm{pNZ} 123$ & This study \\
\hline pTRK703 & $\mathrm{Em}^{\mathrm{r}} ;$ L. lactis pepN on pTRKH2 & This study \\
\hline pTRK704 & $\mathrm{Cm}^{\mathrm{r}}$; L. lactis pepXP on $\mathrm{pNZ} 123$ & This study \\
\hline pTRK705 & $\mathrm{Cm}^{\mathrm{r}} ;$ L. lactis pepC on $\mathrm{pNZ} 123$ & This study \\
\hline pTRK706 & $\mathrm{Cm}^{\mathrm{r}} ;$ Lb. helveticus pepO on pNZ123 & This study \\
\hline pTRK707 & $\mathrm{Em}^{\mathrm{r}} ; \mathrm{P} 15 \mathrm{~A} 10$ on $\mathrm{pTRKH} 2$ & This study \\
\hline pTRK708 & $\mathrm{Em}^{\mathrm{r}} ;$ L. lactis pepC on pTRK707 & This study \\
\hline pTRK709 & Em $^{\mathrm{r}} ;$ L. lactis pepN on pTRK707 & This study \\
\hline pTRK710 & $\mathrm{Em}^{\mathrm{r}} ;$ P15A10 on pTRK568 & This study \\
\hline pTRK711 & $\mathrm{Em}^{\mathrm{r}} ;$ P15A10 on pTRK528 & This study \\
\hline pTRK712 & Em $^{\mathrm{r}}$; L. lactis pepA on pTRK711 & This study \\
\hline pTRK713 & $\mathrm{Em}^{\mathrm{r}} ;$ L. lactis pepO on pTRK711 & This study \\
\hline pTRT001 & Em $^{\mathrm{r}}$; L. lactis pepXP on pTRKH2 & This study \\
\hline pTRT002 & $\mathrm{Cm}^{\mathrm{r}} ;$ L. lactis pepA on $\mathrm{pNZ} 123$ & This study \\
\hline pTRT003 & $\mathrm{Cm}^{\mathrm{r}} ;$ L. lactis pepO on $\mathrm{pNZ} 123$ & This study \\
\hline pTRT004 & Em $^{\mathrm{r}} ;$ L. lactis pepA on pTRK707 & This study \\
\hline pTRT005 & $\mathrm{Em}^{\mathrm{r}} ;$ L. lactis pepO on pTRK707 & This study \\
\hline pTRT006 & Em $^{\mathrm{r}}$; L. lactis pepA on pTRK710 & This study \\
\hline pTRT007 & Em $^{\text {r }}$ L. lactis pepO on pTRK710 & This study \\
\hline
\end{tabular}

${ }^{\mathrm{a}}$ Abbreviations: $\mathrm{Em}^{\mathrm{r}}$, erythromycin resistance; $\mathrm{Cm}^{\mathrm{r}}$, chloramphenicol resistance.

${ }^{\mathrm{b}}$ James Steele, Dept. of Food Science, University of Wisconsin-Madison.

${ }^{\mathrm{c}}$ Gibco-BRL, Grand Island, N.Y.

pand High Fidelity PCR system (Roche Molecular Biochemicals). Synthesized oligonucleotides were obtained from Integrated DNA Technologies (Coralville, Iowa). When blunt-end inserts were required, Pwo DNA polymerase (Roche Molecular Biochemicals) was used.

\section{Plasmid Constructions}

The plasmids constructed in this study are listed in Table 1 . A $3.8 \mathrm{~kb}$ insert carrying the $L$. helveticus pepN gene (Christensen et al., 1995) was obtained from pSUW32 by digestion with $\mathrm{XbaI}$ and then ligated into pTRKH2 (O'Sullivan and Klaenhammer, 1993) and pNZ123 (de Vos, 1987) to produce pTRK701 and pTRK702 respectively. The other peptidase (PEP) genes were amplified from $L$. helveticus CNRZ32 and L. lactis MG1363 with their own transcription and translation start sites, with the exception of the L. lactis pep $O$ where the translation initiation region originates in the oligopeptide transport system operon (Mierau et al., 1993). The primers used to amplify the Lactobacillus and Lactococcus peptidases are listed in Table 2. To construct vectors that encode both Tac31A of the lytic bacteriophage $\phi 31$ and the peptidase genes, the $3.0 \mathrm{~kb}$ fragment containing lacZ.st on pTRK391 was removed by digestion with PstI/SalI. T4 DNA polymerase (Roche Molecular Biochemicals) was used to create blunt ends, followed by ligation and transformation into $E$. coli XL1-Blue to create the vector pTRK707. All five of the lactococcal peptidases were then amplified using Pwo DNA polymerase and the primers described in Table 2 to create fragments with blunt ends. The PCR products were purified prior to ligation with pTRK707, which had been digested with $E c o R V$ (See Figure 1 for a diagram of this construct). The genes for PepA, PepC, PepN, and PepO were cloned into pTRK707 to construct pTRT004, pTRK708, pTRK709, and pTRT005, respectively. Figure 2 depicts the construction of pTRK711 and its derivatives. The $0.8 \mathrm{~kb}$ insert carrying the phage promoter $\mathrm{P}_{15 \mathrm{~A} 10}$ was obtained from pTRK391 by diges- 
Table 2. Primer sets used for the construction of peptidase overexpression vectors.

\begin{tabular}{|c|c|c|c|c|}
\hline Gene & Primer set & Enzyme sites & Size & Reference $^{a}$ \\
\hline $\operatorname{pep} N^{\mathrm{c}}$ & F-CGAGATCTGCGGACGTTTCGGATGAGCCTAATTA & $B g l \mathrm{II} / S a c \mathrm{I}$ & $3.0 \mathrm{~kb}$ & Tan et al., (1992) \\
\hline & R-GCGAGCTCGCGGAAGTCAAGCTCTTCAAGCACTT & & & \\
\hline рерХP & 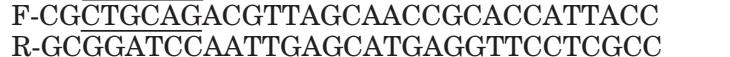 & Pst $\mathrm{I} /$ Bam HI & $2.8 \mathrm{~kb}$ & Nardi et al., (1991) \\
\hline pepXP & $\begin{array}{l}\text { F-GCCTCGAGGAGTAGGGCAGTTCCAACAA } \\
\text { R-GCCTCGAGATGAGGTTCCTCGCCATAGA }\end{array}$ & XhoI/XhoI/ & $2.8 \mathrm{~kb}$ & Nardi et al., (1991) \\
\hline рерC & $\begin{array}{l}\text { F-GCAGTACTACCCGTGGCTTTTAGAAGCA } \\
\text { R-GCGAGCTCTCGTATTCCAGACTCTGTCC }\end{array}$ & $S c a \mathrm{I} / S a c \mathrm{I}$ & $1.7 \mathrm{~kb}$ & Chapot et al., (1993) \\
\hline pep $O^{\mathrm{b}}$ & $\begin{array}{l}\text { F-CGAAGCTTGGCTTTCGACTATCGCAGAT } \\
\text { R-CGCTCGAGAACTTGCCAATGACCCGTGA }\end{array}$ & HindIII/XhoI & $2.3 \mathrm{~kb}$ & Chen and Steele, (1998) \\
\hline рерO & 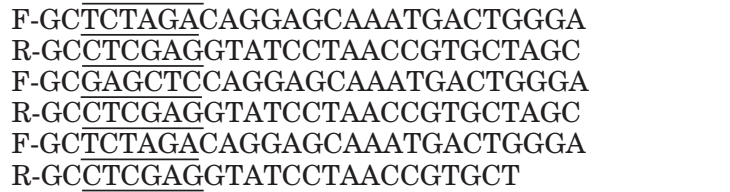 & $\begin{array}{l}\text { XbaI/XhoI } \\
\text { SacI/XhoI }\end{array}$ & $\begin{array}{l}2.5 \mathrm{~kb} \\
2.5 \mathrm{~kb} \\
2.5 \mathrm{~kb}\end{array}$ & Mierau et al. (1993) \\
\hline
\end{tabular}

Restriction sites are underlined.

Abbreviations: F, forwad primer; R, reverse primer.

${ }^{a}$ Genetic sequence reference.

${ }^{b}$ Peptidase amplified from $L b$. helveticus CNRZ32 genome; all other peptidase were amplified from L. lactis MG1363.

tion with $S m a \mathrm{I}$ and ligated into the same site downstream of P144 in pTRK528 (Allison and Klaenhammer, 1996) to construct pTRK711. The L. lactis PepA and PepO coding regions were amplified to contain their ribosomal binding sites, without a native promoter, using the primers listed in Table 2. The peptidase fragments were cloned behind P144 (Djordjevic et al., 1997) in pTRK711.

\section{Bacterial Transformations}

Ligations were transformed into RbCl-competent $E$. coli XL1-Blue strains. RbCl-competent $E$. coli cells were prepared and transformed using the heat-shock method of transformation described for $\mathrm{CaCl}_{2}$-competent cells (Sambrook et al., 1989). After screening E. coli transformants for the proper insert size and orientation, plasmid DNA was isolated and electroporated into competent L. lactis NCK203 cells using a modification of the procedure described by Holo and Nes (1989). A culture of L. lactis was inoculated (1\%) into GM17 and grown until an $\mathrm{OD}_{600}$ of 0.6 was reached. The cells were then washed thee times with ice-cold electroporation buffer $(0.5 \mathrm{M}$ sucrose, $10 \%$ (vol/vol) glycerol) and resuspended in $1 / 10$ of the original volume of this same buffer. Electroporations were carried out as described previously (Walker and Klaenhammer, 1998).

\section{Enzyme Assays}

L. lactis cells $(1 \mathrm{ml})$ were harvested at an $\mathrm{OD}_{600}$ of 0.6 . The supernatant was harvested and the pelleted cells were washed once with $20 \mathrm{mM}$ Tris- $\mathrm{HCl}(\mathrm{pH}$ 6.5) assay buffer. The washed cells were then resuspended in $1 \mathrm{ml}$ of this same buffer. For chromogenic substrates, the following procedure was adapted from Mierau et al. (1996) for the measurement of enzyme activity. Permeation of the membrane was accomplished by adding $5 \mu \mathrm{l}$ of toluene to $1 \mathrm{ml}$ of resuspended cells. Incubation of this mixture was done at $37^{\circ} \mathrm{C}$ for $30 \mathrm{~min}$ to facilitate toluene evaporation. Para-nitroanilide (pNA) substrates (Sigma) were used at $1 \mathrm{mg} / \mathrm{ml}$ concentrations. Individual molar concentrations of each substrate, suspended in $20 \mathrm{mM}$ Tris- $\mathrm{HCl}$ ( $\mathrm{pH} 6.5$ ), were $0.54 \mathrm{mM} \mathrm{L-}$ lysine-pNA for PepN and PepC, $0.76 \mathrm{mM}$ L-glutamic acid- $\gamma$-pNA for PepA, $0.50 \mathrm{mM}$ gly-pro-pNA for PepXP, and $1.69 \mathrm{mM} \mathrm{N}$-Benzoyl-val-gly-arg-pNA, $1.47 \mathrm{mM} \mathrm{N}$ Benzoyl-pro-phe-arg-pNA, and $1.47 \mathrm{mM}$ N-Benzoylphe-val-arg-pNA for PepO. The tubes were incubated in a $37^{\circ} \mathrm{C}$ water bath after the addition of $300 \mu \mathrm{l}$ of the appropriate substrate to $1 \mathrm{ml}$ samples of cell or supernatant fractions. The reactions were stopped after $10 \mathrm{~min}$ with $500 \mu \mathrm{l}$ of $30 \%$ (vol/vol) acetic acid. Cellular debris was removed by centrifugation and spectrophotometric readings were taken at $410 \mathrm{~nm}$. Enzyme activity 

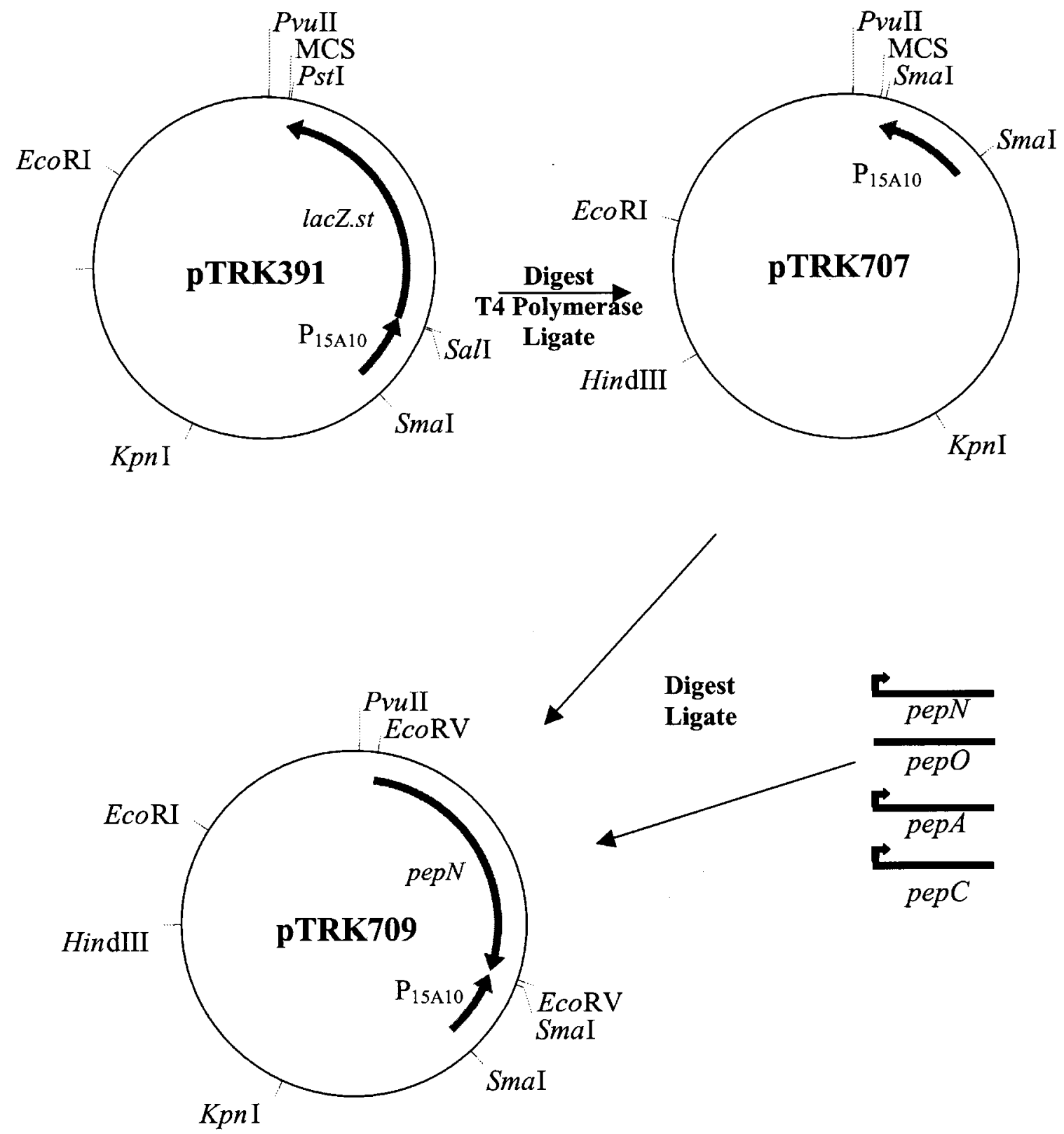

Figure 1. Construction of vectors encoding Tac31A and the peptidase genes. The lacZ.st gene of pTRK391 (Walker and Klaenhammer, 2001) was excised to create pTRK707. Plasmid pTRK707 was digested with EcoRV and ligated to the peptidase fragments amplified with Pwo polymerase. Orientation was determined though restriction enzyme digestion patterns. MCS, multiple cloning site.

is presented as the change in absorbance $(410 \mathrm{~nm})$ per minute.

For fluorogenic substrate assays, cell and supernatant fractions were placed on ice for 10 min prior to bead-beating. Chilled cell fractions were added to tubes that contained silica beads (106 micron diameter) and exposed to three 1-min cycles in a Mini Bead Beater (Biospec Products, Bartlesville, Okla.). The tubes were placed on ice for $1 \mathrm{~min}$ between each beating cycle. Cellular debris and beads were removed by centrifuga- tion. Each $50 \mu$ l sample of cell extract or supernatant was placed in a $400 \mu \mathrm{l}$ well within a black, Nunc Maxisorp 96-well microtiter plate (Nalge Nunc International, Rochester, NY). The substrates used were Larginine-7-amido-4-methylcoumarin (MCA) for PepN and PepC, L-glutamic acid- $\beta$-MCA, L-aspartic acid- $\gamma$ MCA, and N-glutaryl-L-phenylalanine-MCA for PepA, gly-pro-MCA for PepXP, and N-Benzoyl-phe-val-argMCA and N-Benzoyl-arg-MCA for PepO (all MCA substrates were obtained from Sigma). The substrates were 

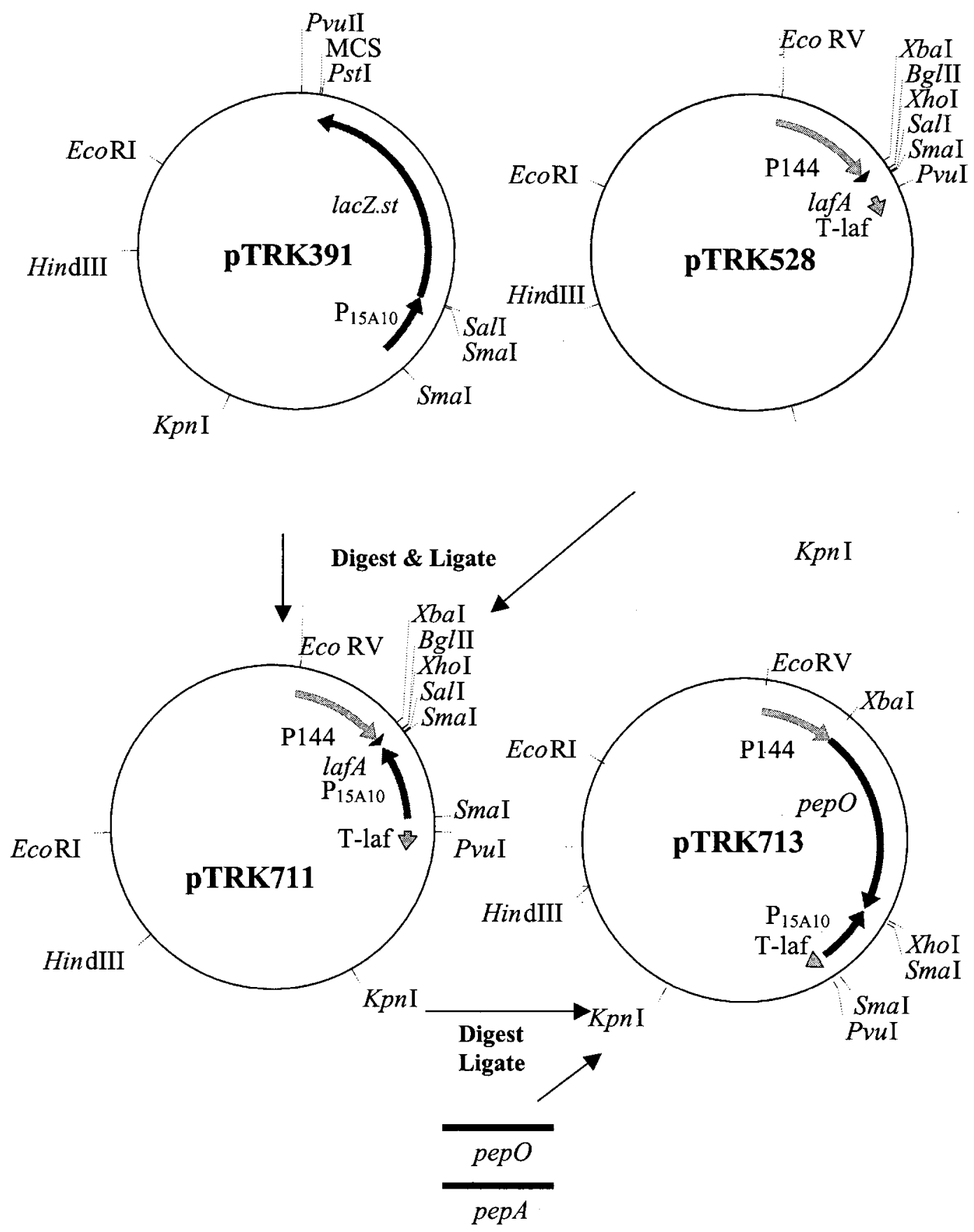

Figure 2. Construction of PepO and PepA expression vectors with the P144 promoter. Plasmid pTRK391 was digested with SmaI to isolate $\mathrm{P}_{15 \mathrm{~A} 10}$ and the fragment was ligated to SmaI digested pTRK528 vector (Allison and Klaenhammer, 1996) to create pTRK711. The promoterless pepA and pepO genes were amplified by PCR and cloned downstream of P144 on pTRK711 as XbaI/SalI (PepA) or XbaI/XhoI (PepO) fragments.

initially dissolved in dimethyl sulfoxide, diluted Tris$\mathrm{HCl}(\mathrm{pH} 6.5)$ and added to a final assay concentration of $0.2 \mathrm{mM}$. The substrates were added immediately before placing the microtiter plate into the CytoFluor ${ }^{\circledR}$ II fluorescence multi-well plate reader (PerSeptive Biosystems, Inc., Framingham, MA). The reader collected data every $2 \mathrm{~min}$ at room temperature for a total of 30 minutes. Three readings per well were taken during each scan and the average of these thee values was recorded. A gain value of 50 was used with excitation and emission wavelengths of $360 \mathrm{~nm}$ and $460 \mathrm{~nm}$, respectively. Standard curves were used to calculate sub- 
strate hydrolysis rates $(\mathrm{nmol} / \mathrm{min})$ and percentages were determined with the formula ( $\mathrm{nmol} / \mathrm{min}$ ) superna$\operatorname{tant} /((\mathrm{nmol} / \mathrm{min})$ supernatant $+(\mathrm{nmol} / \mathrm{min})$ cell extract $)$ $\times 100$. It should be noted that as a cysteine aminopeptidase, PepC required $5 \mathrm{mM}$ dithiotheitol to achieve reduced conditions. In addition, since both PepN and $\mathrm{PepC}$ are general aminopeptidases and hydrolyze the same type of substrates, it was necessary to also add $1 \mathrm{mM}$ EDTA to the PepC reaction wells in order to chelate the metal cofactors required by PepN. This assured that only PepC activity was being detected. Finally, the two-component PepO procedure was performed as stated in Lian et al. (1996) using Succinylarg-pro-phe-his-leu-leu-val-tyr-MCA as a substrate and $50 \mathrm{mM}$ ammonium acetate (pH 7.0) as a buffer. Briefly, the sample and substrate were incubated at $37^{\circ} \mathrm{C}$ for the desired time and stopped by adding the PepO enzyme inhibitor, phosporamidon, to a final concentration of $5 \mu M$. The PepO activity produces two smaller PepM sensitive peptides. The addition of $4 \mu \mathrm{g}$ of commercially prepared PepM (Sigma) for a further 60 min liberates the MCA for fluorescent detection. The amount of MCA released by PepM is proportional to the amount of original substrate hydrolyzed by PepO. Fluorescence was measured using the CytoFluor ${ }^{\circledR}$ II plate reader and hydrolysis rates and percentages were calculated as stated above.

\section{RESULTS}

\section{Construction of Vectors for the Overexpression of Peptidases}

A series of vectors were constructed to facilitate the overexpression of several Lactococcus (PepA, PepC, PepN, PepO, and PepXP) and Lactobacillus (PepN and PepO) peptidases. With the exception of the $L$. helveticus pepN gene, the peptidase genes were amplified by PCR from $L$. lactis subsp. cremoris MG1363 or $L$. helveticus CNRZ32 genomic DNA and directionally cloned into high-copy vectors pTRKH2 (O'Sullivan and Klaenhammer, 1993) and pNZ123 (de Vos, 1987). The L. helveticus pepN gene was subcloned as a $3.8 \mathrm{~kb} \mathrm{XbaI}$ fragment from pSUW32 (Christensen et al., 1995) into both high-copy vectors.

\section{Detection of Peptidase Activity Using p-Nitroanilide Substrates}

Para-nitroanilide (pNA) assays were performed on $L$. lactis NCK203 and its derivatives transformed with the plasmids encoding the peptidase genes. Enzymatic activities were detected only for Lactococcus PepN and

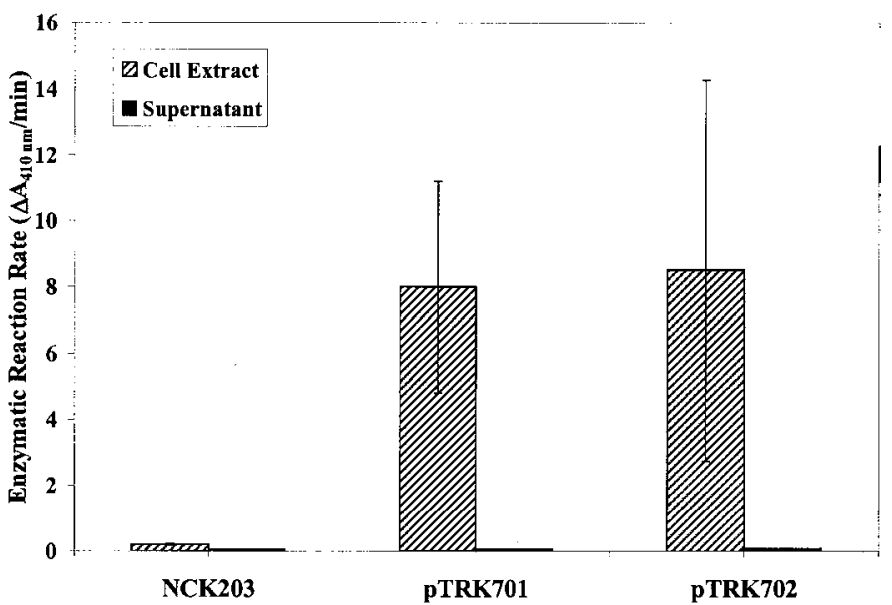

Figure 3. PepN activities detected by chomogenic pNA substate assays in the cells and supernatant of L. lactis NCK203 wildtype and pTRK701 and pTRK702 transformants. Plasmids pTRK701 and pTRK702 encode the L. helveticus PepN on pTRKH2 and pNZ123, respectively.

PepXP and Lactobacillus PepN activities using pNA substrates. PepA, PepO and PepC were not detected by pNA assays in wildtype NCK203 or transformants with the plasmid-encoded pep genes under any conditions (data not shown).

L. lactis NCK203 wild-type PepN activity was low. Expression of the L. helveticus PepN from either highcopy vector caused an increase in cell-associated activity (Figure 3), but the levels were highly variable using pNA substrates. In contrast, PepXP activity was found to be consistently high in wild type L. lactis NCK203 cells (Figure 4). PepXP activity was not increased sub-

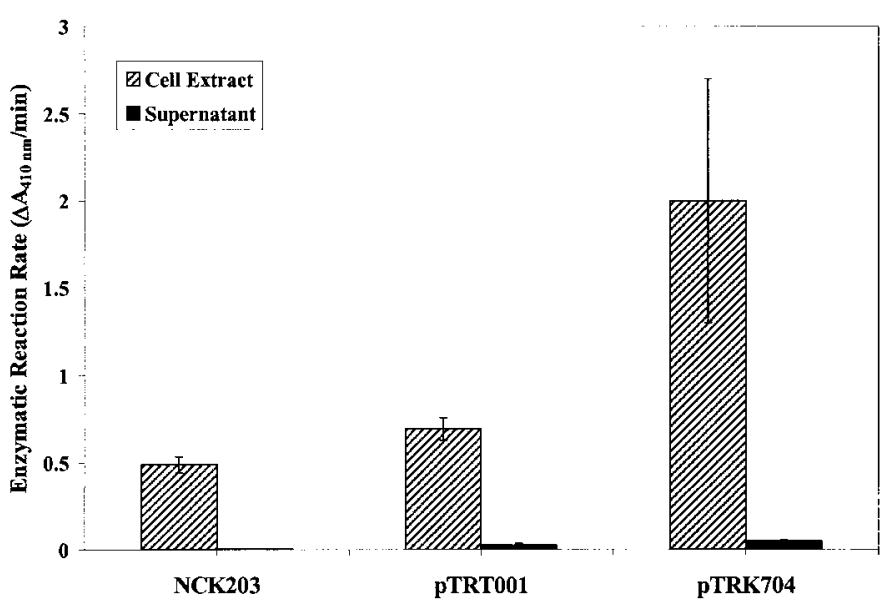

Figure 4. PepXP activities detected by chomogenic pNA substrate assays in the cells and supernatant of L. lactis NCK203 wildtype and pTRT001 and pTRK704 transformants. Plasmids pTRT001 and pTRK704 encode the L. lactis PepXP on pTRKH2 and pNZ123, respectively. 


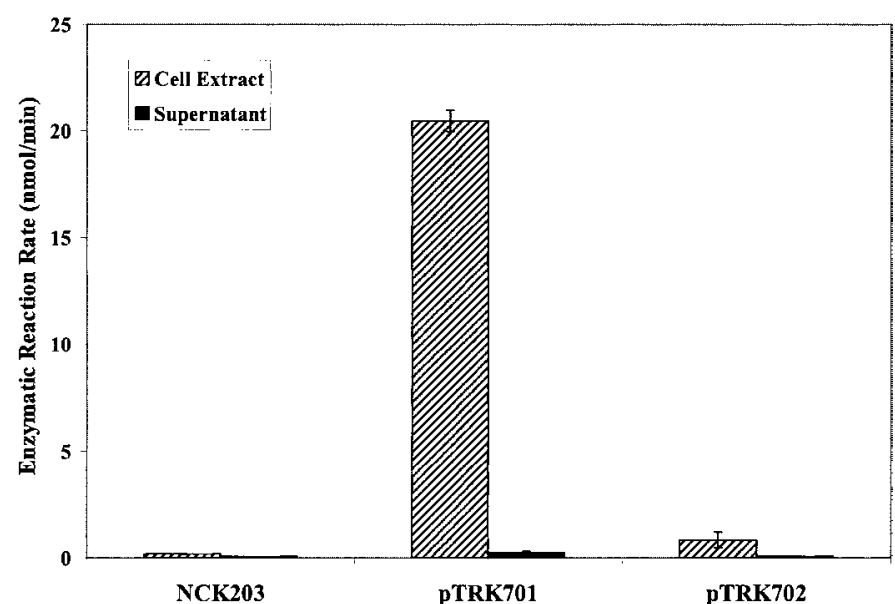

Figure 5. PepN activities detected by fluorogenic MCA substrate assays in the cells and supernatant of L. lactis NCK203 wildtype and pTRK701 and pTRK702 transformants. Plasmids pTRK701 and pTRK702 encode the $L$. helveticus PepN on pTRKH2 and pNZ123, respectively.

stantially over the wildtype levels when cloned into the high-copy vector pTRKH2 but PepXP expressed from pNZ123 produced significantly more activity than $L$. lactis NCK203 cells (Figure 4).

\section{Detection of Peptidase Activity Using 7-Amido-4-Methylcoumarin Substrates}

The assays performed with the pNA substrates were repeated with 7-amino-4-methylcoumain (MCA) substrates because of the inability of the pNA assays to detect the PepC, Pep O and PepA activity and the variability in the levels of peptidase activity detected with pNA substrates. The MCA peptidase substrates, which generate a fluorescent product after enzymatic hydrolysis provided a considerable advantage due to the absence of background interference. The results obtained with the MCA substrates revealed significant differences in PepN activity between strains harboring pepN on pNZ123 and pTRKH2-based vectors. PepN activity associated with cells harboring the pTRKH2 construct was significantly higher compared to both the wildtype and the pNZ123-based construct (compare Figure 3 and 5). Native PepXP levels remained high in $L$. lactis NCK203 and the pNZ123:pepXP construct (pTRK704) produced higher activity levels than the wildtype or when the pepXP was encoded on pTRKH2 (Figure 6).

\section{Detection of Peptidase Externalization Using 7-Amido-4-Methylcoumarin Substrates}

To assess externalization of the peptidases from leaky lactococcal cells, pepA, pepC, pep $N$, and pepO were

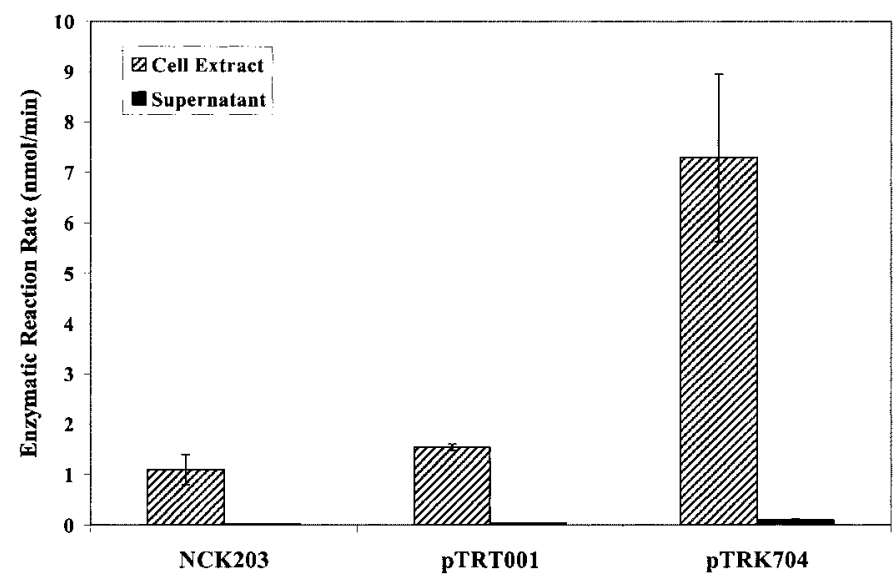

Figure 6. PepXP activities detected by fluorogenic MCA substrate assays in the cells and supernatant of L. lactis NCK203 wildtype and pTRT001 and pTRK704 transformants. Plasmids pTRT001 and pTRK704 encode the $L$. lactis PepXP on pTRKH2 and pNZ123, respectively.

cloned into pTRK707 (Figure 1), a derivative of pTRK391 that encodes Tac31A (O'Sullivan et al., 1996). A plasmid encoding both Tac31A and PepXP was previously constructed in our laboratory (Walker and Klaenhammer, 2001). Lactococcal strains harboring these plasmids were subjected to MCA assays to detect peptidase activity in the cells and supernatants (Figure 7). Introduction of the pepN and рерC genes on pTRK707 resulted in a significant increase in the activity of these enzymes over background levels. Native

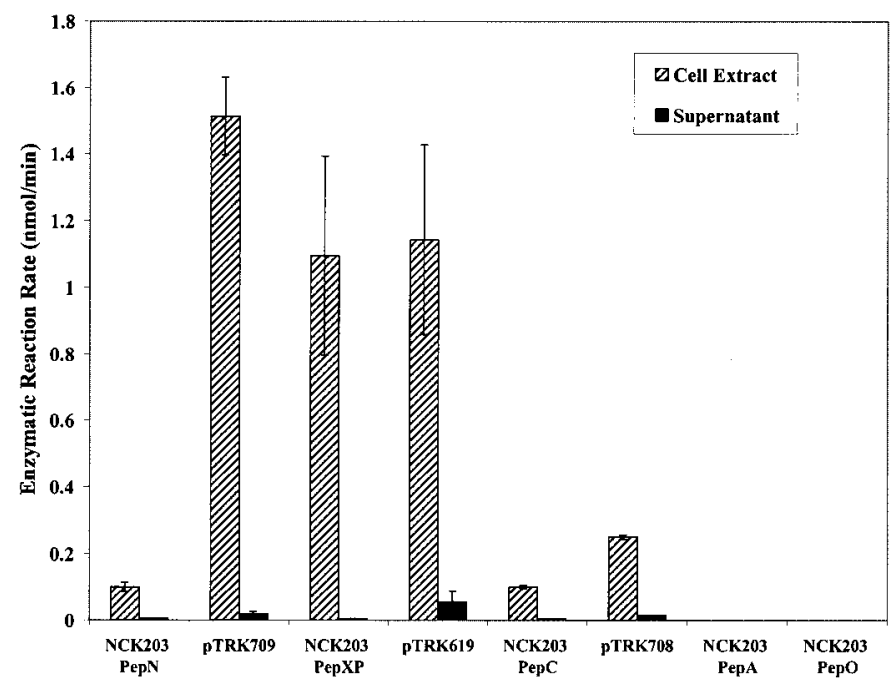

Figure 7. Peptidase activities in the cells and supernatants of L. lactis NCK203 wildtype and with vectors encoding Tac31A and lactococcal peptidase genes. Enzyme activity associated with cell (thatched bars) and the supernatant (solid bars) fractions was detected by fluorogenic MCA substrate assays. 
Table 3. Percentage of peptidase activity found in the supernatant fraction of wild type L. lactis NCK203 and strains harboring leaky, overexpression vectors.

\begin{tabular}{lll}
\hline Peptidase & Vector present & $\%$ Activity in supernatant \\
\hline Aminopeptidase A & - $^{\mathrm{a}}$ & $0.00 \%$ \\
& pTRK712 & $0.00 \%$ \\
Aminopeptidase C & - & $0.00 \%$ \\
& pTRK708 & $5.72 \%$ \\
Aminopeptidase N & - & $0.00 \%$ \\
& pTRK709 & $1.24 \%$ \\
Endopeptidase O & - & $1.87 \%$ \\
& pTRK713 & $3.12 \%$ \\
X-prolyl-dipeptidyl & - & $3.76 \%$ \\
aminopeptidase & pTRK619 & $4.62 \%$ \\
\hline
\end{tabular}

a_, wild type L. lactis NCK203, no vector constructs present.

PepXP activity was again not significantly effected by the presence of extra copies of pepXP on a pTRKH2 derivative. However, the presence of Tac31A on these constructs, which resulted in the externalization of the $\beta$-gal enzyme, did not result in detectable levels of PepN, PepXP or PepC in the supernatants. Although the peptidases were significantly expressed, less than $6 \%$ of their total activity was found in supernatant fractions (Table 3). PepA and PepO activities remained below detection limits and it could not be determined whether or not they were externalized.

\section{Construction of Vectors for the Overexpression and Externalization of PepO and PepA Using Alternative Strong Promoters}

No measurable enzyme activity was detected during preliminary peptidase assays using either pNA or MCA substrates on strains harboring vectors constructed to overexpress PepA or PepO. Therefore, new high-copy vectors were created to place a strong promoter upstream of each of the two pepA and pepO genes. Initially, transcriptional fusions were made with the $L a c$ tobacillus acidophilus P6 promoter (Djordjevic et al., 1997) and the pepA and pep $O$ genes. These vectors were stable in $E$. coli XLI-Blue but deletions occurred after transformation into L. lactis NCK203 (data not shown). Transcriptional fusions were also made to the pepA and pepO genes with the Lactobacillus paracasei $\mathrm{P} 144$ promoter (Djordjevic et al., 1994) using the cloning strategies illustrated in Figure 2. In contrast to the plasmid encoding the P6 promoter, plasmids pTRK712 and pTRK713 appeared to be stable both in $E$. coli and L. lactis. These vectors also encoded Tac31A in order to induce leaky behavior when introduced into lactococcal cells.

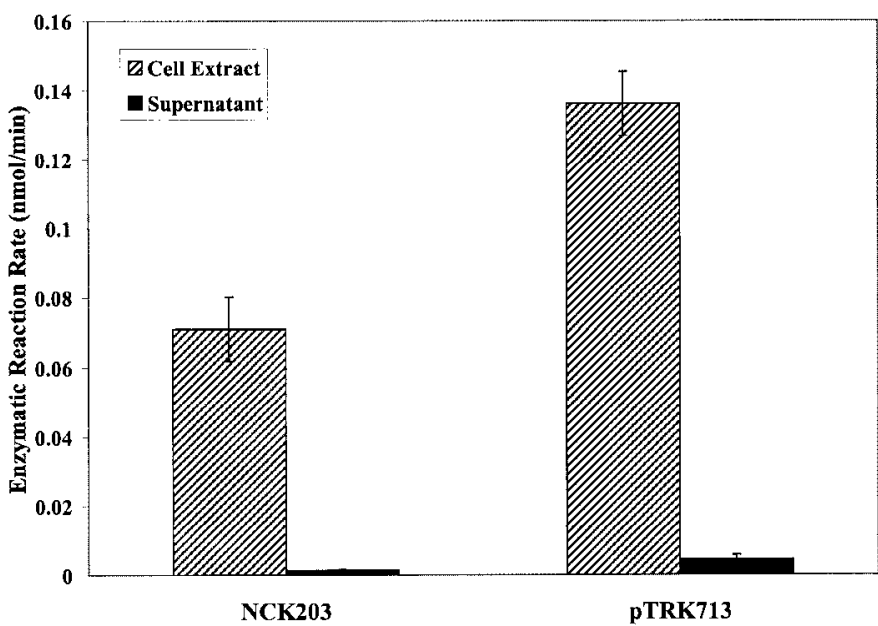

Figure 8. PepO activities in the cells and supernatants of $L$. lactis NCK203 wildtype and NCK203 with pTRK713. Plasmid pTRK713 encodes the $L$. lactis pepO gene under the control of the strong Lactobacillus promoter P144 on a high-copy vector containing Tac31A. Enzyme activity associated with cell and the supernatant fractions was determined by fluorogenic MCA substrate assays as described by Lian et al. (1996).

\section{Detection of PepO and PepA Externalization Using a Modified Assay Procedure with 7-Amido-4-Methylcoumarin Substrates}

PepO activity could not be detected using the short N-Benzoyl-phe-val-arg-pNA or N-Benzoyl-arg-MCA substrates. However, using the Succinyl-X ${ }_{8}-\mathrm{MCA}$ substrate described by Lian et al. (1996), activity was detected in cell free extracts of L. lactis NCK203 and doubled by introducing pepO behind P144 on pTRK713 (Figure 8). PepA also required modified assay conditions to detect activity when expressed behind the P144 promoter. The PepA assay employed the N-glutaryl-Lphe-MCA substrate for an extended incubation time (1 h), at an elevated incubation temperature $\left(55^{\circ} \mathrm{C}\right)$, and with concentrated cell extracts (100-fold). Wildtype levels of PepA activity were determined and a 2 -fold increase in activity were detected in cells when pepA was expressed behind P144 on pTRK707 (Figure 9). The presence of Tac31A on the same plasmid did not result in the externalization of either PepA or PepO activities (Table 3).

The overall amount of PepA activity detected was three to four logs less than the amounts produced by the other four peptidases. To explore if PepA enzymatic activity was affected by $\mathrm{pH}$, reactions were carried out at six different $\mathrm{pH}$ levels between 6.0 and 8.5 and at various $\mathrm{pH}$ levels after a $15 \mathrm{~h}$ incubation period at $55^{\circ} \mathrm{C}$ (Table 4). The activity was also assayed after 10 and 60 min of incubation, but these values were very low and showed no discernable difference among the differ- 


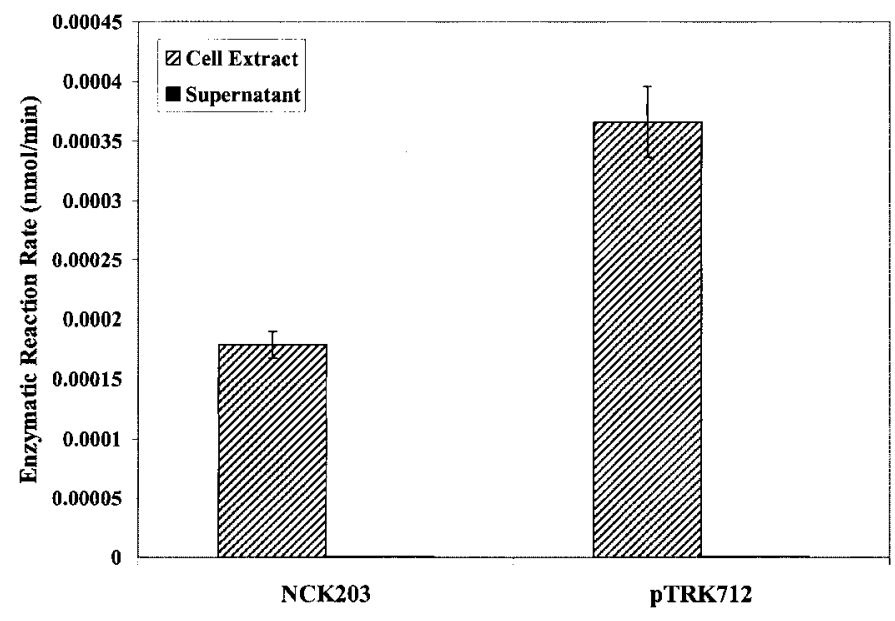

Figure 9. PepA activities in the cells and supernatants of $L$. lactis NCK203 wiltype and NCK203 with pTRK712. Plasmid pTRK712 encodes the L. lactis pepA gene under the control of the strong Lactobacillus promoter P144 on a high-copy vector containing Tac31A. Detection of enzyme activity associated with the cell and supernatant fractions was done by fluorogenic MCA substrate assays under modified conditions (see text for details).

ent $\mathrm{pH}$ levels (data not shown). The data in Table 4 indicate that PepA is most active at $\mathrm{pH} 7.0$, and extended periods of time are required to detect a significant level of activity. After $15 \mathrm{~h}$ of incubation, no PepA activity was detected in the supernatant.

\section{DISCUSSION}

This paper describes the cloning and overexpression of several Lactococcus lactis peptidases (PepA, PepC, PepN, PepO and PepXP) and Lactobacillus helveticus peptidases (PepN and PepO) on two different high-copy vectors ( $p$ TRKH2 and pNZ123). It also describes the cloning of the lactococcal peptidases into pTRK707 (pTRKH2: $\mathrm{P}_{15 \mathrm{~A} 10}$ ), the vector responsible for producing a leaky phenotype, to determine if they could be exter- nalized from the prophage-containing L. lactis subsp. lactis NCK203. The results showed that the level of peptidase overexpression varied considerably among the different enzymes investigated and that none were externalized at significant levels by leaky lactococci.

The PepN activity levels detected in Lactococcus in this study are similar to the results of Chistensen et al. (1995) and Van Alen-Boerrigter et al. (1991). Christensen et al. (1995) reported a 180-fold increase in activity when the L. helveticus CNRZ32 PepN was expressed from a high-copy vector (pIL253) in L. lactis subsp. cremoris LM0230. Van Alen-Boerrigter et al. (1991) found a 20 -fold increase in activity when the L. lactis MG1363 PepN was cloned into pIL253 and transformed into L. lactis subsp. cremoris MG1363. We observed a 40-fold increase in activity with the pIL253-based pTRK701. In addition, the MCA assays revealed significantly higher levels of activity when $p e p N$ was encoded on pTRKH2 than the pNZ123-based pTRK702. In contrast to PepN, the pepXP gene on pTRKH2 failed to increase PepXP levels above the high wildtype levels, but pepXP on pNZ123 increased PepXP activity by a factor of seven. Previous attempts to overexpress PepXP on pTRKH2 were unsuccessful (Walker and Klaenhammer, 2001). Two additional studies have attempted to overexpress $L$. helveticus pepXP genes with varying results. Yuksel and Steele (1996) cloned the CNRZ32 pepXP gene into both a low-copy (pGK12; Kok et al., 1984) and a high-copy vector (pIL253). None of the constructs increased PepXP activity in L. lactis LM0230. However, when the pGK12 based-vector was placed back in CNRZ32, a 4-fold increase in activity was observed. In contrast, Luoma et al. (2001) found a 5 -fold increase in activity when the L. helveticus 53/7 PepXP was cloned into a low-copy pGK12 derivative and placed in L. lactis MG1363. The significance of the different reported peptidase activities cannot be resolved in the absence of mRNA analysis and a direct

Table 4. Level of PepA activity detected in strains of L. lactis NCK203 after overnight $(15 \mathrm{~h})$ incubation at $55^{\circ} \mathrm{C}$ under variable $\mathrm{pH}$ conditions. ${ }^{\text {ab }}$

\begin{tabular}{|c|c|c|c|c|c|c|c|}
\hline Vector & Fraction & $\mathrm{pH} 6.0$ & $\mathrm{pH} 6.5$ & $\mathrm{pH} 7.0$ & $\mathrm{pH} 7.5$ & $\mathrm{pH} 8.0$ & $\mathrm{pH} 8.5$ \\
\hline - & $\mathrm{C}$ & 0.00 & 0.00 & 0.39 & 0.00 & 0.00 & 0.00 \\
\hline$-^{\mathrm{c}}$ & $\mathrm{C}$ & 1.11 & 1.84 & 2.78 & 1.96 & 1.95 & 1.28 \\
\hline - & $\mathbf{S}$ & 0.00 & 0.00 & 0.00 & 0.00 & 0.00 & 0.00 \\
\hline pTRK712 & $\mathrm{C}$ & 0.00 & 0.00 & 0.92 & 0.00 & 0.00 & 0.00 \\
\hline pTRK712 & $\mathrm{C}$ & 2.32 & 2.65 & 4.09 & 3.29 & 3.19 & 1.90 \\
\hline pTRK712 & $\mathbf{S}$ & 0.00 & 0.00 & 0.00 & 0.00 & 0.00 & 0.00 \\
\hline
\end{tabular}

${ }^{a}$ Overnight incubation was done using $0.2 \mathrm{mM}$ N-glutaryl-L-phe-MCA in a covered 96-well microtiter plate. Data shown represent the nanomoles of substrate hydrolyzed after $15 \mathrm{~h}$ of incubation.

${ }^{\mathrm{b}}$ Abbreviations: -, wild type L. lactis NCK203, contains no overexpression vector; C, cell extract; S, supernatant.

${ }^{\mathrm{c}} 100$-fold concentrations were made by harvesting $50 \mathrm{ml}$ of cells by centrifugation and resuspension in $0.5 \mathrm{ml}$ of the appropriate buffer. 
comparison of the copy number of each vector encoding the different pep genes.

There are less data available on the overexpression of the other three peptidases investigated in this study. Only recently has data been published on the cloning and expression of a $L$. helveticus pepC in L. lactis MG1363. Luoma et al. (2001) reported a doubling of PepC activity when cloned on the low-copy vector pGK12. In this study, the L. lactis pepC gene was cloned into the high-copy vector pTRKH2 along with Tac31A in an attempt to determine whether PepC was externalized by the Tac31A-induced leaky state. Unexpectedly, the $L$. lactis pepC expressed on a high-copy vector produced approximately the same increase in activity as the low-copy pGK12 pepC construct.

To our knowledge, this study describes the first report of the overexpression of the Lactococcus PepO and PepA in L. lactis. All previous studies have utilized concentration and purification methods to detect activity. Cloning of these two enzymes required additional expression signals and tailored assay conditions in order to detect activity. In addition to cloning a strong promoter (P144) in front of pepO, the two-component assay procedure described by Lian et al. (1996) was successfully adopted for measuring PepO activity in cell free extracts. Overexpression in pTRK528: $\mathrm{P}_{15 \mathrm{~A} 10}:$ pepO produced twice as much $\mathrm{PepO}$ activity as the wild type strain. However, it should be noted that after 15 min, a plateau effect occurred even when the $\mathrm{PepO}$ assays were performed with excess substrate (data not shown). This effect may be linked to the fact that hydrolysis of the MCA substrate by PepO produces two small non-fluorescent oligopeptides (6 and 4 molecules in length). It has been shown that lactococcal endopeptidases have the ability to hydrolyze a variety of different peptide bonds within a variety of different-sized oligopeptides (Baankreis et al., 1995; Lian et al., 1996; Tan et al., 1991). Because it lacks active site specificity, PepO has the ability to hydrolyze the newly released N-terminal peptide instead of the original, intact MCA peptide substrate. If the peptidase cleaves these smaller N-terminal peptides, which do not have a fluorescent MCA molecule attached to them, the accurate measurement of hydrolysis becomes compromised. Therefore, even though the results displayed a plateauing of activity, suggesting substrate exhaustion, it is possible that $\mathrm{PepO}$ was interacting and cleaving peptides that do not possess detectable fluorescent markers.

Of the peptidases investigated, PepA activity proved the most difficult to detect. A study by Exterkate and de Veer (1987) tested over 30 different substrates with a lactococcal PepA to determine its hydrolytic activity towards various peptides and synthetic substrates. Specificity was found towards peptides possessing N- terminal L- $\alpha$-glutamyl or L- $\alpha$-aspartyl groups with free $\gamma$-carboxyl groups. It was believed that the structure of these alpha amino groups reduced steric hindrance and allowed for proper alignment of the substrate in the active site. In the study by Exterkate and de Veer (1987), only nine out of the 30 substrates tested fit these requirements, and only one was still commercially available as a MCA derivative, N-glutaryl-L-phe-MCA. After several rounds of assay optimization, a measurable amount of activity was attained when a 100 -fold cell extract concentration was incubated at $\mathrm{pH} 7.0$ and $55^{\circ} \mathrm{C}$ for $1 \mathrm{~h}$. However, even with the assay modifications and determination of optional $\mathrm{pH}$ conditions for PepA, the level of PepA activity detected was significantly lower than that of the other peptidases.

After successful expression and detection of these peptidases was accomplished, their externalization was investigated. Walker and Klaenhammer (2001) had shown previously that leaky lactococci externalized $85 \%$ of the intracellular enzyme $\beta$-galactosidase. $\beta$-gal is a $117 \mathrm{kDa}$ monomer and is thought to be functional only as a dimer or tetramer suggesting the leaky system could potentially export molecules up to $500 \mathrm{kDa}$ in size without the need for secretion or export signals. Young and Blasi (1995) discussed the apparent lack of specificity that holin proteins have shown in the past towards different heterologous lysin proteins. If the holin proteins supposedly facilitated the non-specific externalization of lysins, then it was plausible that peptidases would leak via this system. In the $E$. coli $\lambda$ bacteriophage lysis model described by Young and Blasi (1995), it is believed that holin proteins, which are produced during the late expression phase of the phage lytic cycle, associate with the membrane just prior to the release of progeny phage. Once oligomerized across the cell membrane, a conformational change occurs allowing the lysin proteins to cross the membrane where they begin cleaving the peptidoglycan layer and ultimately cause cell lysis. The leaky state may occupy a small window between compromised cell membrane integrity and complete cell lysis. Since all of the peptidases under investigation in this study range between $30-100 \mathrm{kDa}$ (as monomers) in size, it was projected that they might also be released by cells in a leaky condition. The fact that the peptidases were not released into the supernatant of the leaky cells suggests that protein size is not the determining factor for externalization.

In conclusion, over the course of this study, vectors were constructed with several Lactococcus and Lactobacillus peptidases. Two different enzymatic assay techniques were employed for the detection of peptidase activity both in the cells and supernatants. It was established that lactococcal peptidases do not leak out of leaky lactococci under the conditions investigated in 
this study. The mechanism responsible for the leaky state remains unknown. Efforts are underway to control the leaky versus lysis condition, thereby defining avenues to deliver peptidases and other useful proteins (i.e. vaccines, bioactive peptides, etc.) out of the cell without compromising membrane integrity and overall cell viability.

\section{ACKNOWLEDGMENTS}

This research was supported in part by the Southeast Dairy Foods Research Center and Dairy Management, Inc. The authors would also like to thank Jeffrey Christensen and James Steele for providing peptidase constructs and assistance with assays. We also thank Robert Kelly, Lara Chang, W. Michael Russell and Joseph Sturino for their insights and helpful discussions throughout this study.

\section{REFERENCES}

Allison, G. E. and T. R. Klaenhammer. 1996. Unpublished results. Baankreis, R. 1992. The role of lactococcal peptidases in cheese ripening. Ph.D., University of Amsterdam.

Baankreis, R., S. van Schalkwijk, A. C. Alting, and F. A. Exterkate. 1995. The occurrence of two intracellular oligoendopeptidases in Lactococcus lactis and their significance for peptide conversion in cheese. Appl. Microbiol. Biotech. 44:386-392.

Bhowmik, T., L. Fernandez, and J. L. Steele. 1993. Gene replacement in Lactobacillus helveticus. J. Bacteriol. 175:6341-6344.

Buist, G., H. Karsens, A. Nauta, D. van Sinderen, G. Venema, and J. Kok. 1997. Autolysis of Lactococcus lactis caused by induced overproduction of its major autolysin, AcmA. Appl. Environ. Microbiol. 63:2722-2728.

Chapot-Chartier, M. P., M. Nardi, M. C. Chopin, A. Chopin, and J. C. Gripon. 1993. Cloning and sequencing of pepC, a cysteine aminopeptidase gene from Lactococcus lactis subsp. cremoris AM2. Appl. Environ. Microbiol. 59:330-333.

Chen, Y. S. and J. L. Steele. 1998. Genetic characterization and physiological role of endopeptidase $\mathrm{O}$ from Lactobacillus helveticus CNRZ32. Appl. Environ. Microbiol. 64:3411-3415.

Christensen, J. E., E. G. Dudley, J. A. Pederson, and J. L. Steele. 1999. Peptidases and amino acid catabolism in lactic acid bacteria. Antonie Van Leeuwenhoek 76:217-246.

Christensen, J. E., D. L. Lin, A. Palva, and J. L. Steele. 1995. Sequence analysis, distribution and expression of an aminopeptidase Nencoding gene from Lactobacillus helveticus CNRZ32. Gene 155:89-93.

Crow, V. L., T. Coolbear, P. K. Gopal, F. G. Martley, L. L. McKay, and H. Riepe. 1995. The role of autolysis of lactis acid bacteria in the ripening of cheese. Int. Dairy J. 5:855-875.

de Ruyter, P. G., O. P. Kuipers, W. C. Meijer, and W. M. de Vos. 1997. Food-grade controlled lysis of Lactococcus lactis for accelerated cheese ripneing. Nat. Biotech. 15:976-979.

de Vos, W. M. 1987. Gene cloning and expression in lactic streptococci. FEMS Microbiol. Rev. 46:281-295.

Djordjevic, G., B. Bojovic, A. Banina, and L. Topisirovic. 1994. Cloning of promoter-like sequences from Lactobacillus paracasei subsp. paracasei CG11 and their expression in Escherichia coli, Lactococcus lactis, and Lactobacillus reuteri. Can. J. Mirobiol. 40:10431050.

Djordjevic, G., B. Bojovic, N. Miladinov, and L. Topisirovic. 1997. Cloning and molecular analysis of promoter-like sequences isolated from the chromosomal DNA of Lactobacillus acidophilus ATCC 4356. Can. J. Microbiol. 43:61-69.
El Soda, M. 1997. Control and enhancement of flavour in cheese. In: B. A. Law (Ed.), Microbiology and Biochemistry of Cheese and Fermented Milk, 2nd ed. Blackie Academic and Professional, London, England. pp. 219-246.

Exterkate, F. A. and G. de Veer. 1987. Purification and some properties of a membrane-bound aminopeptidase A from Streptococcus cremoris. Appl. Environ. Microbiol. 53:577-583.

Farkye, N. Y. 1999. Cheese: Microbiology of cheese making and maturation. In: R. K. Robinson, C. A. Batt and P. D. Patel (Eds), Encyclopedia of Food Microbiology, Vol. 1. Academic Press, San Diego, CA. pp. 381-387.

Feirtag, J. M. and L. L. Mckay. 1987. Isolation of Streptococcus lactis C2 mutants selected for temperature sensitivity and potential use in cheese manufacture. J. Dairy Sci. 70:1773-1778.

Gasson, M. J. 1983. Plasmid complements of Streptotoccus lactis NCDO 712 and other lactic streptococci after protoplast-induced curing. J. Bacteriol. 154:1-9.

Hill, C., K. Pierce, and T. R. Klaenhammer. 1989. The conjugative plasmic pTR2030 encodes two bacteriophage defense mechanisms in lactococci, restriction modification $(\mathrm{R}+\mathrm{M}+)$ and abortive infection (Hsp+). Appl. Environ. Microbiol. 55:2416-2419.

Holo, H. and I. F. Nes. 1989. High frequency transformation, by electroporation, of Lactococcus lactis subsp. cremoris grown with glycine in osmotically stabolized media. Appl. Environ. Microbiol. 55:3119-3123.

Kok, J., J. van der Vossen, and G. Venema. 1984. Construction of plasmid cloning vectors for lactic streptococci which also replicate in Bacillus subtilis and Escherichia coli. Appl. Environ. Microbiol. 48:726-731.

Kunji, E. R. S., I. Mierau, A. Hagting, B. Poolman, and W. N. Konings. 1996. The proteolytic systems of lactic acid bacteria. Antonie Van Leeuwenhoek 70:187-221.

l'Anson, K. J., S. Movahedi, H. G. Griffin, M. J. Gasson, and F. Mulholland. 1995. A non-essential glutamyl aminopeptidase is required for optimal growth of Lactococcus lactis MG1363 in milk. Microbiology 141:2873-2881.

Lian, W., D. H. Wu, W. N. Konings, I. Mierau, and L. B. Hersh. 1996. Heterologous expression and characterization of recombinant Lactococcus lactis neutral endopeptidase (Neprilysin). Arch. Biochem. Biophy. 333:121-126.

Luoma, S., K. Peltoniemi, V. Joutsjoki, T. Rantanen, M. Tamminen, I. Heikkinen, and A. Palva. 2001. Expression of six peptidases from Lactobacillus helveticus in Lactococcus lactis. Appl. Environ. Microbiol. 67:1232-1238.

Meijer, W., B. van de Bunt, M. Twigt, B. de Jonge, G. Smit, and J. Hugenholtz. 1998. Lysis of Lactococcus lactis subsp. cremoris SK110 and its nisin-immune transconjugant in relation to flavor development in cheese. Appl. Environ. Microbiol. 64:1950-1953.

Mierau, I., E. R. S. Kunji, K. J. Leenhouts, M. A. Hellendoorn, A. J. Haandrikman, B. Poolman, W. N. Konings, G. Venema, and J. Kok. 1996. Multiple-peptidase mutants of Lactococcus lactis are severely impaired in their ability to grow in milk. J. Bacteriol. 178:2794-2803.

Mierau, I., P. S. T. Tan, A. J. Haandrikman, J. Kok, K. J. Leenhouts, W. N. Konings, and G. Venema. 1993. Cloning and sequencing of the gene for a lactococcal endopeptidase, an enzyme with sequence similarity to mammalian enkephalinase. J. Bacteriol. 175:2087-2096.

Nardi, M., M. C. Chopin, A. Chopin, M. M. Cals, and J. C. Gripon. 1991. Cloning and DNA sequence analysis of an X-prolyl dipeptidyl aminopeptidase gene from Lactococcus lactis subsp. lactis NCDO 763. Appl. Environ. Microbiol. 57:45-50.

O’Sullivan, D. J. and T. R. Klaenhammer. 1993. High- and low-copynumber Lactococcus shuttle cloning vectors with featuers for clone screening. Gene 137:227-231.

O'Sullivan, D. J., S. A. Walker, S. G. West, and T. R. Klaenhammer. 1996. Development of an expression strategy using a lytic phase to trigger explosive plasmid amplification and gene expression. Bio/Technology 14:82-87.

Prost, F. and J. F. Chamba. 1994. Effect of aminopeptidase activity of thermophilic lactobacilli on Emmental cheese characteristics. J. Dairy Sci. 77:24-33. 
Sambrook, J., E. F. Fritsch, and T. Maniatis. 1989. Molecular cloning: a laboratory manual. Cold Spring Harbor Laboratory Press, Cold Spring Harbor, N.Y.

Tan, P. S. T., K. M. Pos, and W. N. Konings. 1991. Purification and characterization of an endopeptidase from Lactococcus lactis subsp. cremoris Wg2. Appl. Environ. Microbiol. 57:3593-3599.

Tan, P. S. T., I. J. Van Alen-Boerrigter, B. Poolman, R. J. Siezan, W. M. de Vos, and W. N. Konings. 1992. Characterization of the Lactococcus lactis pep $N$ gene encoding an aminopeptidse homologous to mammalian aminopeptidase N. FEBS Lett. 306:9-16.

Tan, P. S. T., T. A. van Kessel, F. L. van de Veerdonk, P. F. Zuurendonk, A. P. Bruins, and W. N. Konings. 1993. Degradation and debittering of a tryptic digest from $\beta$-casein by aminopeptidase $\mathrm{N}$ from Lactococcus lactis subsp. cremoris Wg2. Appl. Environ. Microbiol. 59:1430-1436.

Terzaghi, B. E. and W. E. Sandine. 1975. Improved medium for lactic streptococci and their bacteriophages. Appl. Microbiol. 29:807813.

Van Alen-Boerrigter, I. J., R. Baankreis, and W. M. de Vos. 1991. Characterization and overexpression of the Lactococcus lactis pepN gene and localization of its product, aminopeptidase $\mathrm{N}$. Appl. Environ. Microbiol. 57:2555-2561.
Vasala, A., M. Valkkila, J. Caldentey, and T. Alatossava. 1995. Genetic and biochemical characterization of the Lactobacillus delbrueckii subsp. lactis bacteriophase LL-H lysin. Appl. Environ. Microbiol. 61:4004-4011.

Walker, D. C. and T. R. Klaenhammer. 1994. Isolation of a novel IS3 group insertion element and construction of an integration vector for Lactobacillus spp. J. Bacteriol. 176:5330-5340.

Walker, S. A. and T. R. Klaenhammer. 1998. Molecular characterization of a phage-inducible middle promoter and its transcriptional activator from the lactococcal bacteriophase $\phi 31$. J. Bacteriol. 180:921-931.

Walker, S. A. and T. R. Klaenhammer. 2001. Leaky Lactococcus cultures that externalize enzymes and antigens independently of culture lysis and secretion and export pathways. Appl. Environ. Microbiol. 67:251-259.

White, B. A. ed. 1997. PCR cloning protocols. Humana Press, Totowa, N.J.

Young, R. and U. Blasi. 1995. Holins: form and function in bacteriophage lysis. FEMS Microbiol. Rev. 17:191-205.

Yuskel, G. U. and J. L. Steele. 1996. DNA sequence analysis, expression, distribution and physiological role of the Xaa-prolyldipeptidyl aminopeptidase gene from Lactobacillus helveticus CNRZ32. Appl. Microbiol. Biotech. 44:766-773. 